\title{
Letter to the Editor on: Online educational resources for orthopaedic residency-a narrative review
}

\author{
Steven R. Carlson ${ }^{1} \cdot$ Lainey G. Bukowiec ${ }^{1} \cdot$ Hunter L. Hasley ${ }^{1} \cdot$ Martinus Megalla $^{1}$
}

Received: 9 August 2021 / Accepted: 23 August 2021 / Published online: 31 August 2021

(c) The Author(s) under exclusive licence to SICOT aisbl 2021

We read the article by Raja et al. [1] regarding online education resources for orthopedic residents with keen interest. As students who entered medical school while our country was deep in the COVID-19 pandemic, we have direct experience consulting the internet for our medical questions, advice, and education materials. In our pursuit of orthopaedics specifically, we have also become aware that many virtual training platforms lack the visuospatial stimuli needed to develop skills that would be useful in surgery. Resulting from this, we feel that there are a few matters pertaining to the methodology and implications of this article that should be addressed.

We agree with the authors about the importance of analyzing the utility and breadth of online resources available to budding orthopaedic surgeons. However, we remain concerned by a prospective future where the internet's massive role taken on during the pandemic will remain after it ends. We worry that the employment of online resources will supplant other training experiences and have a negative effect on our preparation for the operating room. Hands-on activities such as the dissection of cadavers have been shown to result in higher assessment scores of students compared to less involved methods [2]. Still, many curricula across the world have sacrificed dissections and anatomy labs altogether making it clear medical education's evolution may leave preparation for surgical residency behind.

Steven R. Carlson

steven.carlson@hmhn.org

Lainey G. Bukowiec

lainey.bukowiec@hmhn.org

Hunter L. Hasley

hunter.hasley@hmhn.org

Martinus Megalla

martinus.megalla@hmhn.org

1 Hackensack Meridian School of Medicine, 340 Kingsland Street, Nutley, NJ, USA
In this article, widely available online tools such as websites, podcasts, and iPhone applications are comprehensively reviewed to demonstrate the advantages that the internet provides to orthopaedic residents. However, we believe that these educational benefits should not necessarily be discussed in the context of orthopaedic residency without shedding light on the current options for haptic training within the virtual format. Though hands-on virtual training formats often come at a steeper cost, their accessibility has risen recently at some institutions [3]. Therefore, we believe that this study would have drawn benefit from incorporating virtual/augmented reality and remote surgery resources as an additional domain in which to review.

Over the past two decades, computer-assisted orthopaedic surgery has become an area of massive interest and allows physicians to interface with surgical instruments and anatomical structures in the operating room in real-time [4]. Moreover, remote surgery is practically built for learning as it gives hands-on exposure to the surgical environment from home or wherever the student may be. This method of training when applied to acetabular cup placement in total hip arthroplasty has proven in at least one study to be equivalent to one-on-one training by an orthopaedic surgeon [5].

We understand and appreciate the many benefits that online resources provide to resident physicians within a changing landscape of training. We are also grateful for the adaptations in curricula that have been implemented to sustain a rigorous education through the COVID-19 pandemic. Nonetheless, we believe that by ensuring all components of training are included, the union of resident physician education and internet resources could become more specific to orthopaedic surgery.

Availability of data and material Not applicable.

Code availability Not applicable. 


\section{Declarations}

Ethics approval Not applicable.

Consent to participate Not applicable.

Consent for publication Not applicable.

Conflict of interest The authors declare no competing interests.

\section{References}

1. Raja BS, Choudhury AK, Paul S, Rajkumar S, Kalia RB (2021) Online educational resources for orthopaedic residency - a narrative review. Int Orthop 45(8):1911-1922. https://doi.org/10.1007/ s00264-021-05101-6

2. Abdellatif $\mathrm{H}$ (2020) Time spent in practicing dissection correlated with improvement in anatomical knowledge of students: experimental study in an integrated learning program. Cureus 12(4):e7558. https://doi.org/10.7759/cureus.7558

3. Mabrey JD, Reinig KD, Cannon WD (2010) Virtual reality in orthopaedics: is it a reality? Clin Orthop Relat Res 468(10):25862591. https://doi.org/10.1007/s11999-010-1426-1

4. Hernandez D, Garimella R, Eltorai A, Daniels AH (2017) Computer-assisted orthopaedic surgery. Orthop Surg 9(2):152-158. https://doi.org/10.1111/os.12323

5. Logishetty K, Western L, Morgan R, Iranpour F, Cobb JP, Auvinet E (2019) Can an augmented reality headset improve accuracy of acetabular cup orientation in simulated THA? A randomized trial. Clin Orthop Relat Res 477(5):1190-1199. https://doi.org/10.1097/ CORR.0000000000000542

Publisher's note Springer Nature remains neutral with regard to jurisdictional claims in published maps and institutional affiliations. 